\title{
American Journal of
}

\section{Health, Medicine and Nursing Practice}

(AJHMN)

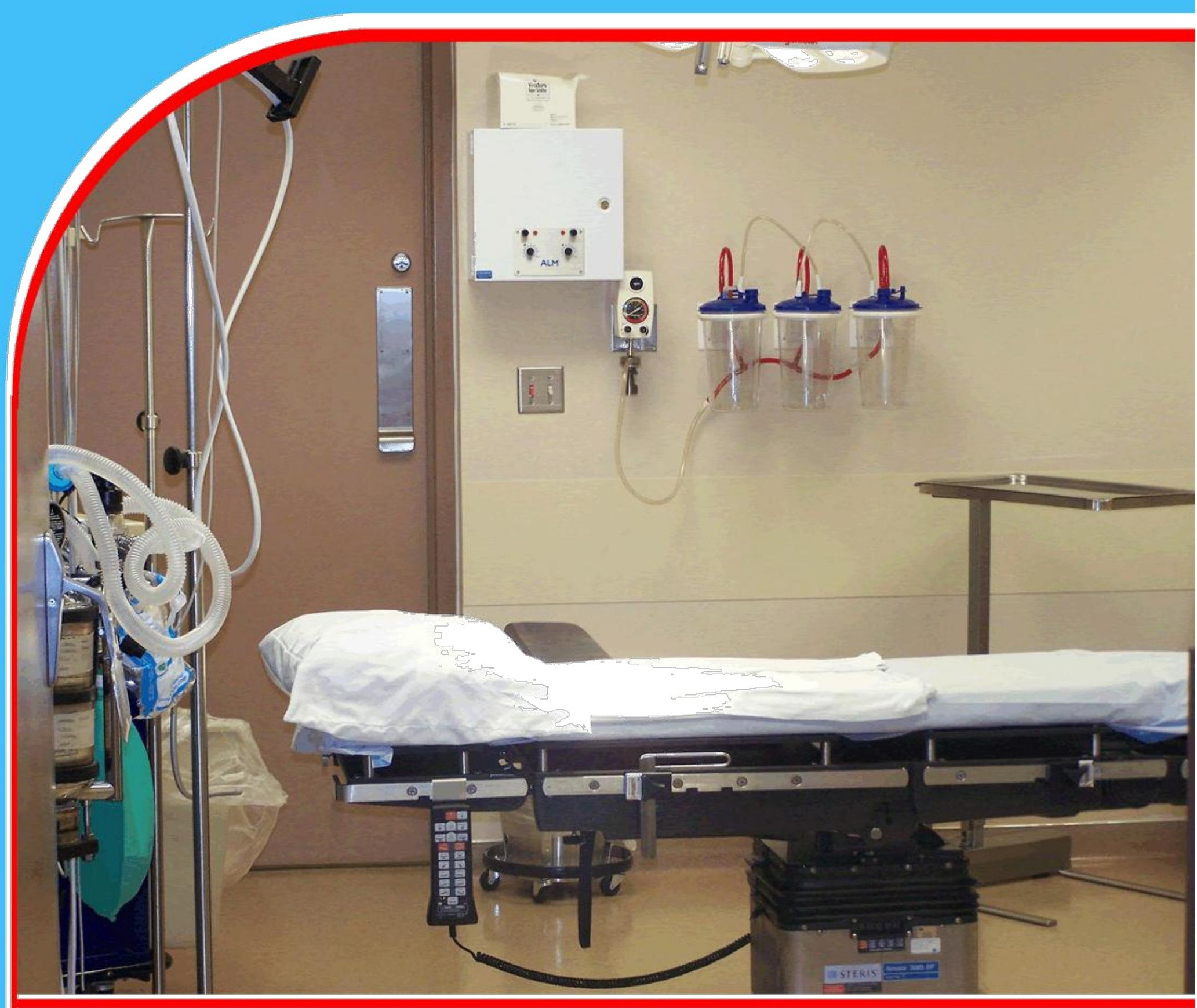

The Impact of COVID 19 Precautionary Measures on Management of Chronic Disease Patients Following in Primary Health Care Centers

Jeddah, Saudi Arabia, 2020

Dr. Jawaher Saleh Mitwalli; Dr.Nouf khaled Njaifan; Dr. Rania Mansor Harere; Dr.Nuha Tariq Sharaf; Dr.Afnan Sabri Owaidah; Dr. Kholoud Mohammed Bamookrah 


\title{
The Impact of COVID 19 Precautionary Measures on Management of Chronic Disease Patients Following in Primary Health Care Centers Jeddah, Saudi Arabia, 2020
}

\author{
Dr. Jawaher Saleh Mitwalli ${ }^{1 *}$; Dr.Nouf khaled Njaifan ${ }^{1}$; Dr. Rania Mansor Harere ${ }^{1}$; Dr.Nuha \\ Tariq Sharaf ${ }^{1}$; Dr.Afnan Sabri Owaidah ${ }^{1}$; Dr. Kholoud Mohammed Bamookrah ${ }^{2}$ \\ ${ }^{1}$ King Fahad Hospital , Ministry of Health, Jeddah, Saudi Arabia \\ ${ }^{2}$ Public Health Administration, Ministry of Health, Jeddah, Saudi Arabia
}

Corresponding author: email: dr.jawaher.mt@hotmail.com

\begin{abstract}
Purpose: Since the declaration of the wide and progressive spread of COVID-19 as a pandemic, the health systems worldwide are facing challenges in the balance between applying recommended precautionary measures for COVID-19, while maintain providing essential routine health care to other groups like chronic diseases' patients. The current study aims to explore impact of precautionary measures of COVID-19 on chronic diseases' patients in Jeddah, Saudi Arabia.
\end{abstract}

Methodology: Through an analytical cross-sectional study; a representative sample of chronic diseases' patients were selected randomly from primary health care centers in Jeddah. They were invited to respond to a valid questionnaire designed to collect data about the impact of Covid 19 pandemic measures on chronic diseases' patients. The questionnaire is adapted from valid published questionnaires conceptualized around the impact of Covid 19 measures on chronic patients. Chi-square test was used to identify association between the health status and the independent variables. P-value $<0.05$ was considered as an indication for significance.

Results: Out of all respondents $(\mathrm{n}=386)$ there was almost equal distribution of females $(52.3 \%)$ and males (47.7\%), and remarkable dominance of Saudis (91.7\%); two thirds (62.7\%) reported one chronic disease while the rest had two or more diseases. Considerable proportions faced difficulties in medical appointments $(43.8 \%)$, reaching physicians $(30.1 \%)$ and obtaining medicines $(16.6 \%)$ during the pandemic. The health status of $23.3 \%$ became worse; especially among those with low income (46.4\%), those who needed emergency care $(57.1 \%)$ and all who did not get it $\mathrm{p}<0.005$.

Conclusion and recommendations: The precautionary measures of COVID-19 have an impact on the care, health status of chronic diseases' patients. Efforts should be made to plan for innovative measures to ensure providing essential health care to chronic diseases' patients during pandemics.

Keywords: Chronic diseases' patients, Covid-19, pandemic, health care services. 


\section{Introduction}

In December 2019, a large number of cases with "pneumonia of unknown origin" was detected in a wholesale market in Wuhan, China, that was defined later as a Novel Coronavirus (COVID-19).(1) With the global spread of the disease, the World Health Organization declared it as COVID-19 pandemic on March 2020.(2) According to the WHO report, although the new coronavirus can affect people in all age, but the risk is high in older age group and people with preexisting Non Communicable Diseases (NCDs).(3) Chronic diseases' patients are facing substantial threats during pandemics, either of being more vulnerable to get infected because of compromised health status, and difficulties in receiving essential routine health care due to redirection of health resources towards control of the pandemic.(4-7) The most common comorbidity observed in critical COVID-19 patients who were admitted in the critical care units in most countries were hypertension, diabetes, and chronic respiratory problems. $(8,9)$ The unprecedented near-complete global lockdown due to COVID-19 pandemic has created major dilemmas for providers in all areas of health-care delivery. The rapid spread of the virus disclosed the weaknesses in health systems. Lack of adequate health-care infrastructure and human resources, serious supply-chain disruptions, and widespread fear among patients and health-care workers have resulted in serious threatening of the patient care and safety.(10) In June, 2020, based on a global survey covering 155 countries worldwide, WHO issued the results which showed that the regular management for NCDs had been severely disrupted since the COVID-19 pandemic began.(11) In Saudi Arabia, the first case was reported on $2^{\text {nd }}$ of March 2020, a Saudi native way back to country from Iran via Bahrain. After that, number of cases increased rapidly. Therefore as a preventive step; lockdown was declared with restriction of tourists and visitors fand the Great Mosque has been closed for safety and sterilization purposes.(12) The review of the published researches showed that there is no previous study on the impact of the precautionary measures on the management of patients with chronic diseases in Jeddah. This study aims to determine the impact of the measures associated with Covid 19 pandemic on the patients with chronic diseases and to identify factors affecting the health status and outcome of chronic diseases patients during the pandemic.

\section{Material and methods:}

Through a cross-sectional analytic study design, 386 chronic diseases' patients were selected randomly from log books of chronic diseases' clinics in primary health care centers. The study included adult diabetic and hypertensive patients who fulfilled the following criteria: Diagnosed since at least six months, has medical record and following the same primary health care center for at least six months. The data were collected by using a questionnaire designed for the impact of Covid 19 pandemic measures on chronic diseases' patients. The questionnaire is comprised of three main domains, first describing demographic characteristics of the respondents; second defining the chronic diseases and the third domain including 12 questions outlining expected impact of Covid 19 precautionary measures on the respondents. The 
questionnaire is adapted from valid published questionnaires conceptualized around the impact of Covid 19 measures on chronic patients.(13,14) Data entry and statistical analysis was done using Statistical Package for Social Science (SPSS) version (20). Quality control was done at the stages of coding and data entry. Categorical variables presented as frequency distribution and percentages. Chi-square test was used to identify any association between the health status and the independent variables Statistical significance was set at P-value $<0.05$ and confidence interval of (95\%). Results are presented in frequency distribution tables, contingency tables and pie charts. The research was approved from the local Institutional Research Board (IRB) in Jeddah before conducting the research.

\section{Results}

Table 1 shows demographic characteristics of the patients $(n=386)$.

Table 1: Socio demographic Characteristics of the study group ( $\mathrm{n}=\mathbf{3 8 6})$.

\begin{tabular}{lcc}
\hline Characteristics & No. & Percentage \\
\hline Gender: & 184 & 47.7 \\
Male & 202 & 52.3 \\
Female & & \\
\hline Nationality: & 354 & 91.7 \\
Saudi & 32 & 8.3 \\
Non Saudi & & \\
\hline Age categories: & 9 & 2.3 \\
$<20$ years & 130 & 33.7 \\
20-<40 years & 143 & 37.0 \\
40-<60 years & 104 & 26.9 \\
$\geq 60$ years & & \\
\hline Marital status: & 71 & 18.4 \\
Single & 280 & 72.5 \\
Married & 27 & 7.0 \\
Divorced & 8 & 2.1 \\
Widowed & & \\
\hline Education level: & 14 & 3.6 \\
Primary & 24 & 6.2 \\
Intermediate & 117 & 30.3 \\
Secondary & 231 & 59.8 \\
University or higher & & \\
\hline Monthly income: & 69 & 17.9 \\
$<5,000$ SR & 120 & 31.1 \\
5,000-<10,000 SR & & \\
\hline & & \\
\hline & & \\
\hline
\end{tabular}




\begin{tabular}{lcc}
\hline Job: & & \\
Has a job & 167 & 43.3 \\
Jobless & 219 & 56.7 \\
\hline Type of housing: & & \\
Flat & 182 & 47.2 \\
Villa & 177 & 45.8 \\
Others & 27 & 7.0 \\
\hline Number of household individuals: & & \\
<4 individuals & 88 & 22.8 \\
4-6 individuals & 203 & 52.6 \\
$>6$ individuals & 95 & 24.6 \\
\hline \hline
\end{tabular}

There was an almost equal distribution of females (52.3\%) and males (47.7\%), with marked dominance of Saudis $(91.7 \%)$. The great majority of the participants aged 20 years or older (a total of $97.3 \%$ ), and the married formed $72.5 \%$. More than one half of them $(59.8 \%)$ had university qualification or higher; with only $17.9 \%$ who had monthly income less than 5,000 SR $(\approx \$ 1,333)$; and $43.3 \%$ pointed that they had a job. Those who are living in flats constituted $47.2 \%$ while those who are living in villas were $45.8 \%$. Most of the participants $(77.2 \%)$ were living within families with an average of four individuals or more [Table 1].

Figure 1 displays distribution of the patients according to the number of chronic diseases they had reported.

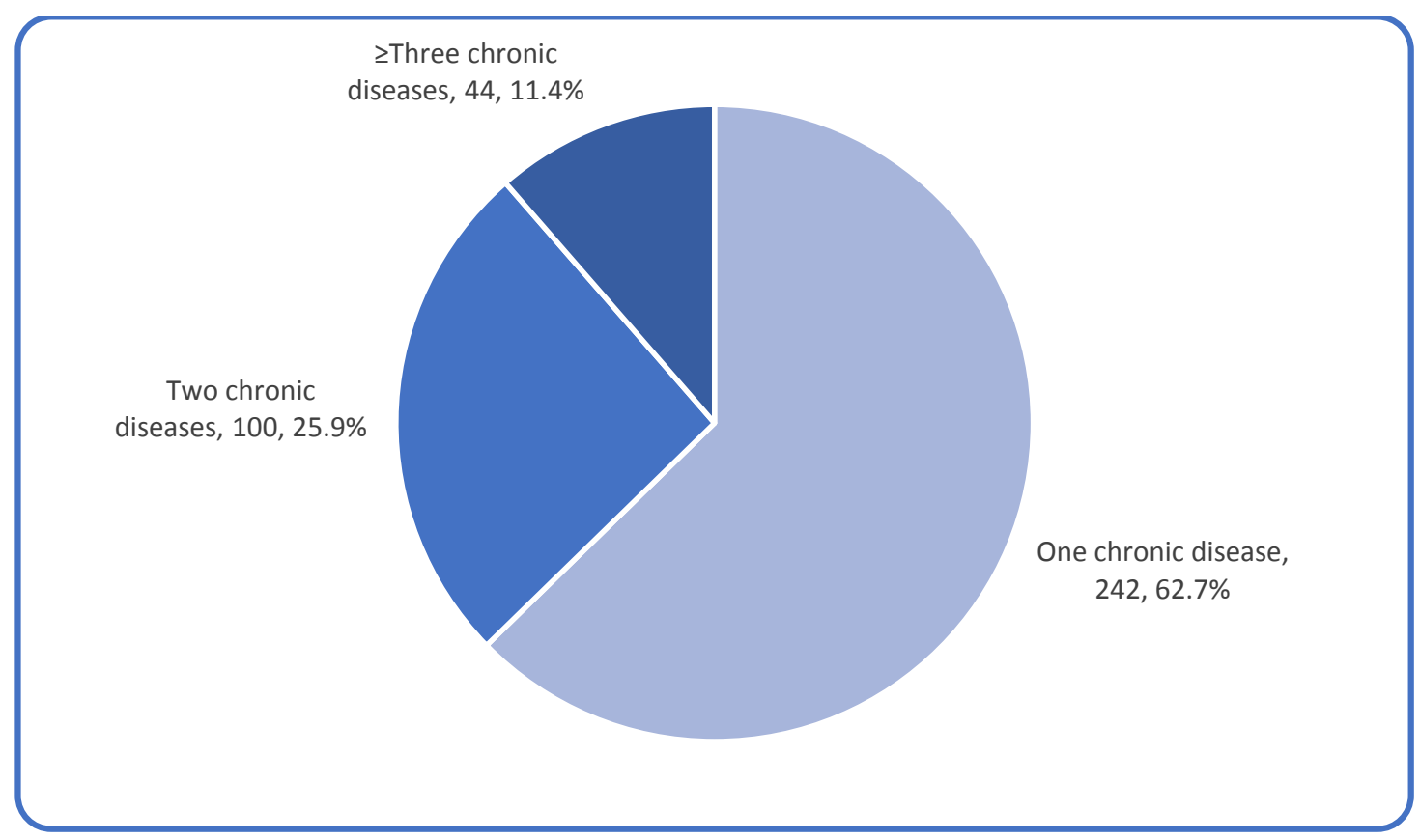

Figure 1: Number of chronic diseases reported by the respondents. 
Almost two thirds of the respondents (62.7\%) reported one chronic disease, while one quarter of them (25.9\%) reported two chronic diseases and $11.4 \%$ had three or more chronic diseases [Figure 1].

Table 2 demonstrates relevant clinical characteristics of the chronic diseases' patients during the pandemic.

Table 2: Clinical characteristics of the patients during the pandemic.

\begin{tabular}{lcc}
\hline \hline Clinical aspects & No. & Percentage \\
\hline Exposure to Covid-19: & 68 & 17.6 \\
Got infected & 103 & 26.7 \\
A household individual got infected & 105 & 27.2 \\
Other family member got infected & 64 & 16.6 \\
\hline Medical care for the chronic disease: & 116 & 30.1 \\
Faced difficulty to obtain medicines & 169 & 43.8 \\
Faced difficulty in reaching physicians & 83 & 21.5 \\
Change or difficulty to get appointment & 77 & 19.9 \\
Harmed from irregular medical care & 58 & 75.3 \\
Needed emergency care & 19 & 24.7 \\
Got the emergency care when needed (n=77) & & \\
Did not get the emergency care when needed (n=77) & 286 & 74.1 \\
\hline Changes in the disease episodes: & 89 & 23.1 \\
No change & 11 & 2.8 \\
Increased frequency of episodes & & \\
Decreased frequency of episodes & & \\
\hline \hline
\end{tabular}

The table shows that $17.6 \%$ of the patients addressed that they had been affected by Covid-12 and $26.7 \%$ had one or more of the direct household individuals affected by Covid19. Regarding the received medical care during the pandemic, $16.6 \%$ of the participants claimed that they faced difficulties in obtaining their medicine, and slightly less than one half (43.8\%) found difficulty or change in the appointments and almost one third of them $(30.1 \%)$ pointed that they faced difficulties in reaching their treating physicians. One of each five patients $(21.5 \%)$ expressed that they got harmed from the irregular medical care during the pandemic, and $24.7 \%$ of the patients who needed emergency care did not get it. Moreover, an overall $23.1 \%$ of the patients expressed that they suffered from increased episodes of the chronic disease [Table 2]. 
Table 3 illustrates the perceived fears of the chronic diseases patients they had encountered during the pandemic.

Table 3: Perceived fears of the chronic diseases' patients during the pandemic.

\begin{tabular}{lcc}
\hline \hline Perceived fears & No. & Percentage \\
\hline $\begin{array}{l}\text { Fears of getting infection while visiting treating } \\
\text { physician: }\end{array}$ & \\
Yes & 254 & 65.8 \\
No & 132 & 34.2 \\
\hline Fears of becoming so ill with unapproachable medical & & \\
care: & 248 & 64.2 \\
Yes & 138 & 35.8 \\
No
\end{tabular}

Two thirds of the patients (65.8\%) felt afraid of getting infected with Covid-19 while visiting their treating physician, and equal percentage (64.2\%) had fears of becoming so ill in milieu of difficult approach to medical care [Table 3].

Figure 2 displays the self-rating of the chronic diseases' patients to the changes of their health status during the pandemic.

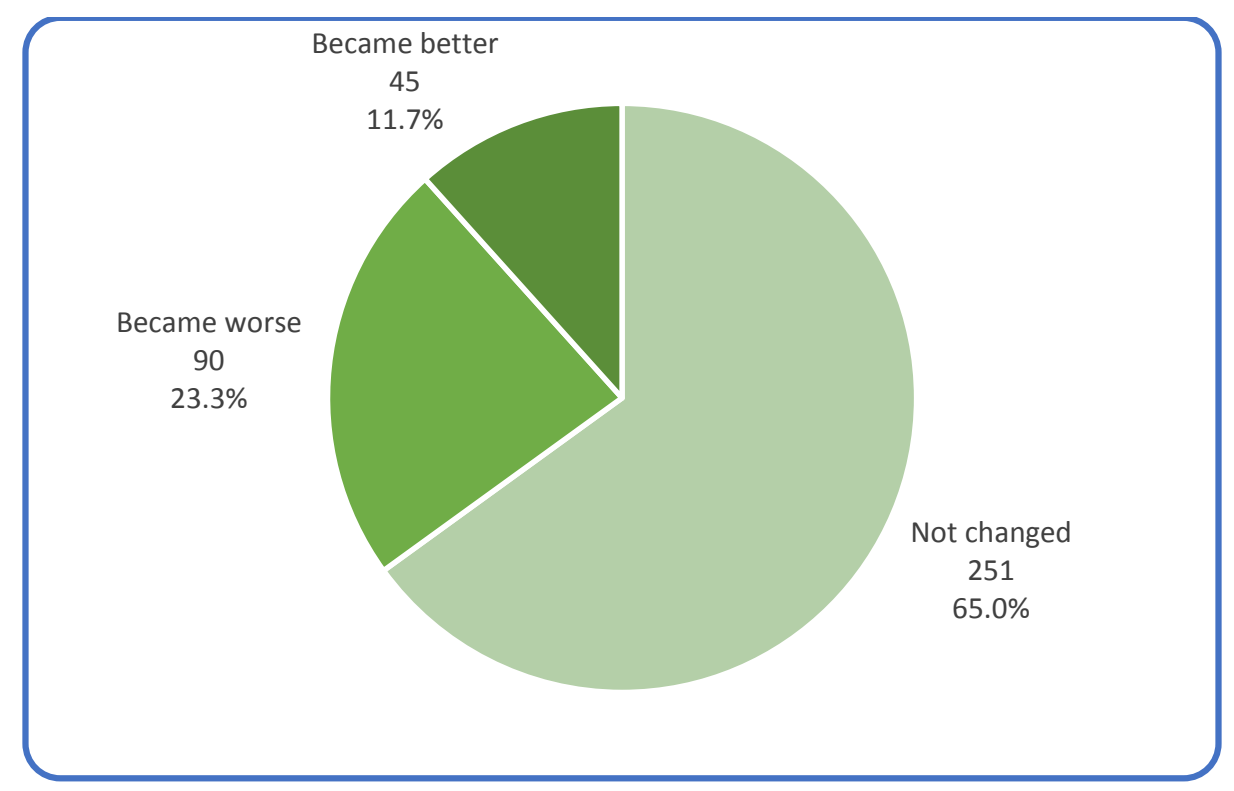

Figure 2: Self-rating for the change in health status during the pandemic.

One quarter of the patients $(23.3 \%)$ claimed that their health status became worse during the pandemic, and the rest were either not changed (65\%) or became better $(11.7 \%)$ [Figure 2]. Table 4 illustrates the differences in the self-rated changes in the health status of the chronic diseases' patients along the pandemic according to their demographic characteristics. 
American Journal of Health, Medicine and Nursing Practice

Table 4: Changes in self-rated changes in the health status of the patients during the pandemic according to their demographic characteristics.

\begin{tabular}{|c|c|c|c|c|c|c|}
\hline \multirow{3}{*}{$\begin{array}{l}\text { Demographic } \\
\text { characteristics }\end{array}$} & \multicolumn{4}{|c|}{ Self-rated health status } & \multirow{3}{*}{$X^{2}$} & \multirow{3}{*}{$\mathrm{P}^{*}$} \\
\hline & \multicolumn{2}{|c|}{$\begin{array}{l}\text { No change or } \\
\text { improved }\end{array}$} & \multicolumn{2}{|c|}{ Became worse } & & \\
\hline & No & $\%$ & No & $\%$ & & \\
\hline \multicolumn{7}{|l|}{ Gender: } \\
\hline Male & 140 & $76.1 \%$ & 44 & $23.9 \%$ & \multirow[b]{2}{*}{0.070} & \multirow[b]{2}{*}{0.791} \\
\hline Female & 156 & $77.2 \%$ & 46 & $22.8 \%$ & & \\
\hline \multicolumn{7}{|l|}{ Nationality: } \\
\hline Saudi & 269 & $76.0 \%$ & 85 & $24.0 \%$ & \multirow[b]{2}{*}{1.154} & \multirow[b]{2}{*}{0.283} \\
\hline Non Saudi & 27 & $84.4 \%$ & 5 & $15.6 \%$ & & \\
\hline \multicolumn{7}{|l|}{ Age categories: } \\
\hline$<20$ years & 8 & $88.9 \%$ & 1 & $11.1 \%$ & \multirow{4}{*}{7.884} & \multirow{4}{*}{$0.048 * *$} \\
\hline $20-<40$ years & 89 & $68.5 \%$ & 41 & $31.5 \%$ & & \\
\hline $40-<60$ years & 114 & $79.7 \%$ & 29 & $20.3 \%$ & & \\
\hline$\geq 60$ years & 85 & $81.7 \%$ & 19 & $18.3 \%$ & & \\
\hline \multicolumn{7}{|l|}{ Education level: } \\
\hline Primary & 9 & $64.3 \%$ & 5 & $35.7 \%$ & \multirow{4}{*}{2.156} & \multirow{4}{*}{0.541} \\
\hline Intermediate & 20 & $83.3 \%$ & 4 & $16.7 \%$ & & \\
\hline Secondary & 92 & $78.6 \%$ & 25 & $21.4 \%$ & & \\
\hline University or higher & 175 & $75.8 \%$ & 56 & $24.2 \%$ & & \\
\hline \multicolumn{7}{|l|}{ Marital status: } \\
\hline Single & 46 & $64.8 \%$ & 25 & $35.2 \%$ & \multirow{4}{*}{7.792} & \multirow{4}{*}{0.051} \\
\hline Married & 220 & $78.6 \%$ & 60 & $21.4 \%$ & & \\
\hline Divorced & 23 & $85.2 \%$ & 4 & $14.8 \%$ & & \\
\hline Widowed & 7 & $87.5 \%$ & 1 & $12.5 \%$ & & \\
\hline \multicolumn{7}{|l|}{ Monthly income: } \\
\hline$<5,000 \mathrm{SR}$ & 37 & $53.6 \%$ & 32 & $46.4 \%$ & \multirow{3}{*}{26.898} & \multirow{3}{*}{$<0.001 * *$} \\
\hline $5,000-<10,000 \mathrm{SR}$ & 93 & $77.5 \%$ & 27 & $22.5 \%$ & & \\
\hline$\geq 10,000 \mathrm{SR}$ & 166 & $84.3 \%$ & 31 & $15.7 \%$ & & \\
\hline \multicolumn{7}{|l|}{ Job: } \\
\hline Has a job & 133 & $79.6 \%$ & 34 & $20.4 \%$ & \multirow[b]{2}{*}{1.439} & \\
\hline Jobless & 163 & $74.4 \%$ & 56 & $25.6 \%$ & & 0.230 \\
\hline Type of housing: & & & & & & \\
\hline Flat & 125 & $68.7 \%$ & 57 & $31.3 \%$ & & \\
\hline Villa & 151 & $85.3 \%$ & 26 & $14.7 \%$ & & \\
\hline Others & 20 & $74.1 \%$ & 7 & $25.9 \%$ & 13.989 & $0.001 * *$ \\
\hline $\begin{array}{l}\text { Number of hous } \\
\text { individuals: }\end{array}$ & & & & & & \\
\hline$<4$ individuals & 65 & $73.9 \%$ & 23 & $26.1 \%$ & & \\
\hline 4-6 individuals & 160 & $78.8 \%$ & 43 & $21.2 \%$ & 1.110 & 0.574 \\
\hline$>6$ individuals & 71 & $74.7 \%$ & 24 & $25.3 \%$ & & \\
\hline
\end{tabular}

* Based on Chi Square ** Statistically significant 
The percentage of those who had worse health status was significantly higher in patients aged $20-<40$ years $(31.5 \%)$, those who had monthly income $<5,000$ SR $(46.4 \%)$ and those who are living in flats $(31.3 \%) \mathrm{p}<0.05$. On the other hand, although the percentages were higher in males $(23.9 \%)$, Saudis (24\%), those who had low education level (35.7\%), single persons (35.2\%), jobless (25.6\%) and those living in a relatively small families (26.1\%), nevertheless, these differences are not statistically significant $\mathrm{p}>0.05$ [Table 4].

Table 5 illustrates the differences in the self-rated changes in the health status of the chronic diseases' patients along the pandemic according to the relevant clinical characteristics.

Table 5: Changes in self-rated health status of the patients during the pandemic according to their clinical characteristics.

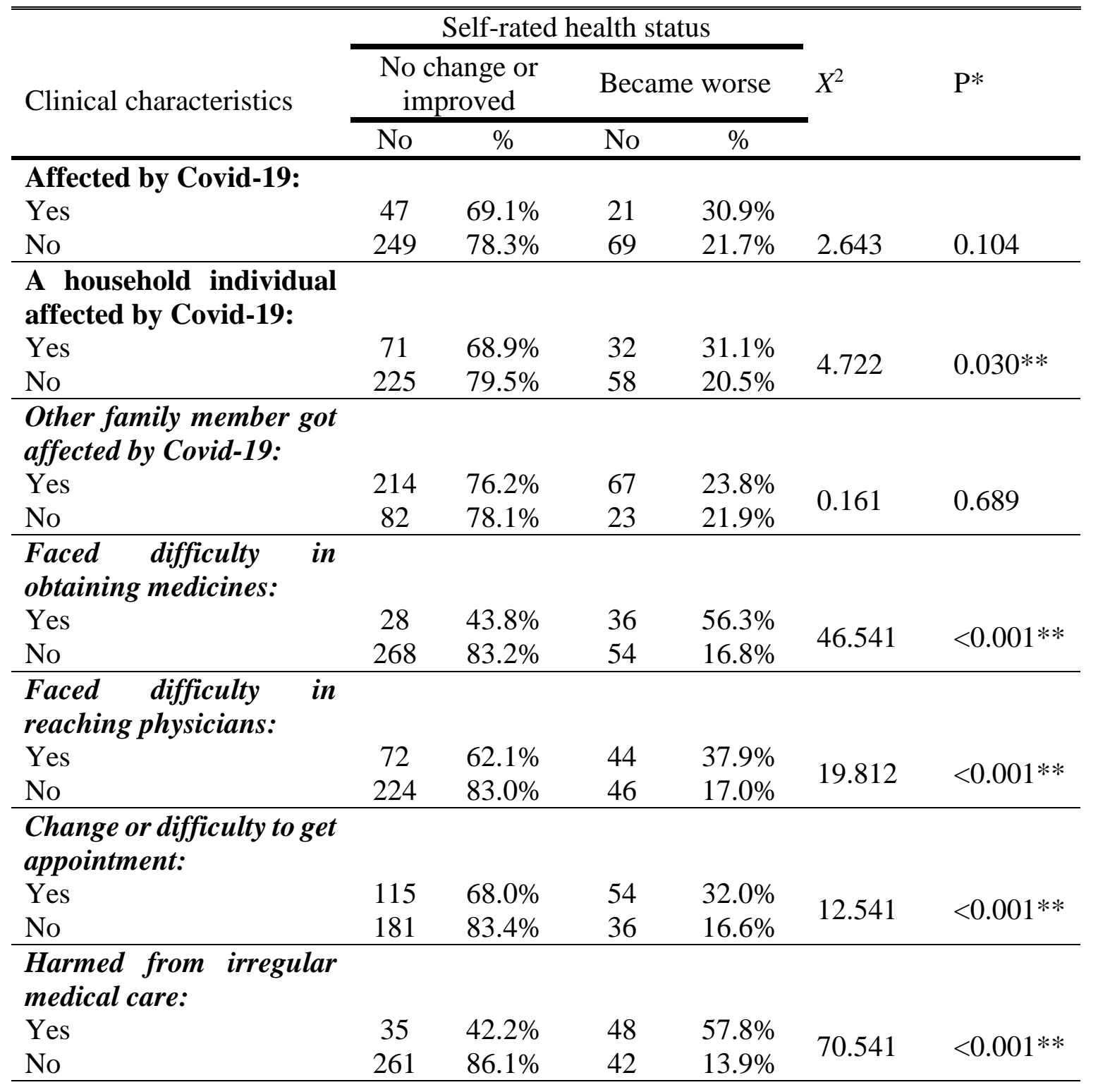




\begin{tabular}{lcccccc}
\hline $\begin{array}{l}\text { Needed emergency care: } \\
\text { Yes }\end{array}$ & 33 & $42.9 \%$ & 44 & $57.1 \%$ & 61.558 & $0.001^{* *}$ \\
No & 263 & $85.1 \%$ & 46 & $14.9 \%$ & & \\
\hline $\begin{array}{l}\text { Changes in the disease } \\
\text { episodes: }\end{array}$ & & & & & & \\
No change & 255 & $89.2 \%$ & 31 & $10.8 \%$ & & \\
Increased & 33 & $37.1 \%$ & 56 & $62.9 \%$ & 103.707 & $0.001^{* *}$ \\
Decreased & 8 & $72.7 \%$ & 3 & $27.3 \%$ & & \\
\hline $\begin{array}{l}\text { Got the emergency care } \\
\text { when needed: }\end{array}$ & & & & & & \\
Yes & 33 & $56.9 \%$ & 25 & $43.1 \%$ & 18.918 & $0.001 * *$ \\
No & 0 & $0.0 \%$ & 19 & $100.0 \%$ & & \\
\hline \hline
\end{tabular}

* Based on Chi Square ** Statistically significant

The percentages of those who had worse status were significantly higher in patients who faced difficulties in reaching their treating physicians (37.9\%), those who had difficulties in getting medical appointment (32\%), those who got harmed from irregular medical care $(57.8 \%)$, those who needed emergency care $(57.1 \%)$, those who experienced increase in the disease episodes $(62.9 \%)$ and all patients $(100 \%)$ who needed emergency care and did not get it $\mathrm{p}<0.05$ [Table 5].

\section{Discussion}

In March 2020, the world health organization (WHO) declared that rapid and aggressive spread of COVID-19 as a pandemic;(11) since then, most of the countries worldwide urgently reallocated its health resources and put the major concern on prevention and control of COVID-19 cases. Accordingly, the Health Economics predicted that "treating patients with chronic conditions would be one of the top challenges facing doctors in 2020".(15) Accordingly, Singh et al (2021) added that "people living with chronic conditions experience the syndemic phenomenon in which the COVID-19 pandemic exacerbates their preexisting chronic condition, already occurring alongside other potentially marginalizing sociopolitical and ecological factors.(16) By time, it was evident that the preventive measures including lockdown and curfew; besides relative shortage of health services provided to routine patients created unprecedent situation. Many subgroups of patients were negatively affected. One of these groups is the chronic diseases patients. The current study showed that a considerable proportion of the chronic diseases' patients faced difficulties in the medical appointments $(43.8 \%)$, reaching their treating physicians $(30.1 \%)$ or obtaining medicines $(16.6 \%)$.

These findings came in accordance to what had been reported in most of the reviewed researches from different countries worldwide; that had been explained by the limited available health resources and restricted transportations as consequences of the lockdowns and preventive measures of COVID-19.(7,17-19) Another reason explaining the difficulties 
claimed by the patients was the limited socialization. Social distancing could play direct and indirect roles in the ability of the caregivers to help some chronic diseases patients to reach health services when needed or bringing medicines. $(20,21)$ Also, the distancing could threaten adherence of the patients to their treatment, particularly in elderly patients.(21) Moreover, the disruption in the routine health services could be attributed to the patients themselves, as shown in the current study, where the patients expressed their fears of getting infected with COVID19 while visiting their treating physicians $(65.8 \%)$; these fears are accentuated by the fears of getting infected and become so ill in the milieu of insufficient health care services. Barach et al (2020) stated that "we must realize that many more serious illnesses and avoidable deaths are likely, not just from COVID-19, but as a consequence of the social disruption it has caused, including the fear, and lack of trust, and structural dysfunction in accessing and paying for medical care".(22) In the current study, the disruption in the health services resulted in worsening of the health status of almost one quarter of our patients $(23.3 \%)$.

The multivariate analysis showed that the worsening was not even in all subgroups. For example, worsening was significantly higher among patients with low monthly income; that could be explained by inability to purchase health services from private sector when it is not feasible in public institutes. Similar findings was addressed by Singh et al (2021) in India.(21) Most of our patients who experienced irregular medical care and increased episodes of the disease claimed that their health status became worse. In this respect, Jacobson et al (2017), through a comparative study for the irregular versus continuous clinical follow-up of diabetic patients, found that patients with irregular follow-up were more likely to experience poor glycemic control and more episodes of diabetic ketoacidosis. Moreover, they were more likely to develop retinopathy due to irregular follow-up.(23) Worsening of the health status was significantly higher in patients who needed emergency care during the pandemic; especially among those who did not get the service when needed. In USA, the researchers recognized a remarkable decline in the ED visits after prioritizing urgent visits to mitigate the spread of COVID-19 in health care settings. The decline included life-threatening health conditions that always necessitate immediate emergency care, the delay or foregone of the needed care might result in serious disability or death.(24) Finally, worse health status was significantly much prominent in patients who expressed that one of the household individuals got COVID-19. In this regards, Adom et al (2020) pointed that "when a person is reported positive for COVID19 , the family are usually singled out from the community" with increase in the time spent indoors which rise common risk factors such as lack of exercise and increased risk.(25) Moreover, it is well understood that the principle concern of the family members are often diverted towards the affected person with COVID-19 rather than any member else, even if being a chronic disease patient. 


\section{Conclusion and recommendations}

The health care professionals are facing challenges in caring for chronic diseases' patients, since they have to balance between protecting them from COVID-19, while managing their chronic condition effectively. A considerable proportion of the patients experienced difficulty to access essential health care, therefore, almost one quarter had worse health status during the pandemic, especially in the relatively low socioeconomic and those who needed emergency care. Basic interventions should be applied using innovative measures such as digital healthcare as mHealth to ensure adequate health services to the chronic diseases' patients during pandemics.

\section{References}

1. Huang C, Wang Y, Li X, Ren L, Zhao J, Hu Y, et al. Clinical features of patients infected with 2019 novel coronavirus in Wuhan, China. Lancet. 2020;395(10223):497-506.

2. World Health Organization. Naming the coronavirus disease (COVID-19) and the virus that causes it. World Health Organization. 2020.

3. Basu S. Non-communicable disease management in vulnerable patients during Covid19. Indian J Med Ethics. 2020;5(2).

4. Saqib MAN, Siddiqui S, Qasim M, Jamil MA, Rafique I, Awan UA, et al. Effect of COVID-19 lockdown on patients with chronic diseases. Diabetes Metab Syndr Clin Res Rev. 2020;14(6):1621-3.

5. Danhieux K, Buffel V, Pairon A, Benkheil A, Remmen R, Wouters E, et al. The impact of COVID-19 on chronic care according to providers: a qualitative study among primary care practices in Belgium. BMC Fam Pract. 2020;21(1):1-6.

6. Klimek L, Jutel M, Bousquet J, Agache I, Akdis CA, Hox V, et al. Management of patients with chronic rhinosinusitis during the COVID-19 pandemic-An EAACI position paper. Allergy Eur J Allergy Clin Immunol. 2021;76(3):677-88.

7. Hacker KA, Briss PA, Richardson L, Wright J, Petersen R. COVID-19 and Chronic Disease: The Impact Now and in the Future. Prev Chronic Dis. 2021;18.

8. Sanyaolu A, Okorie C, Marinkovic A, Patidar R, Younis K, Desai P, et al. Comorbidity and its Impact on Patients with COVID-19. SN Compr Clin Med. 2020;1-8.

9. Leung C. Clinical features of deaths in the novel coronavirus epidemic in China. Reviews in Medical Virology. 2020. p. e2103.

10. Pramesh CS, Badwe RA. Cancer management in India during COVID-19. N Engl J Med. 2020;382(20):e61.

11. World Health Organization. COVID-19 significantly impacts health services for noncommunicable diseases [Internet]. 2020 [cited 2020 Oct 1]. Available from: https://www.who.int/news-room/detail/01-06-2020-covid-19-significantly-impacts- 
health-services-for-noncommunicable-diseases

12. Ameen F, Amna T, Alghamdi AAA, AlKahtani MDF. Covid-19 pandemic outburst in Saudi Arabia: A glimpse. Saudi Journal of Biological Sciences. 2020.

13. Oliver, N., Barber, X., Roomp, K., \& Roomp K. The Covid19Impact Survey: Assessing the Pulse of the COVID-19 Pandemic in Spain via 24 questions. 2020.

14. Rajendran S, Jayagopal P. Accessing Covid19 Epidemic Outbreak in Tamilnadu and the Impact of Lockdown through Epidemiological Models and Dynamic systems. Measurement. 2020;

15. Medical Economics. Top Challenges Number 7: Treating patients with chronic conditions [Internet]. 2019. Available from:

https://www.medicaleconomics.com/view/top-challenges-number-7-treating-patientschronic-conditions

16. Singh K, Kaushik A, Johnson L, Jaganathan S, Jarhyan P, Deepa M, et al. Patient experiences and perceptions of chronic disease care during the COVID-19 pandemic in India: a qualitative study. BMJ Open. 2021;11(6):e048926.

17. Yadav UN, Rayamajhee B, Mistry SK, Parsekar SS, Mishra SK. A Syndemic Perspective on the Management of Non-communicable Diseases Amid the COVID-19 Pandemic in Low- and Middle-Income Countries. Front Public Heal. 2020;8:508.

18. Czeisler MÉ, Marynak K, Clarke KEN, Salah Z, Shakya I, Thierry JM, et al. Delay or Avoidance of Medical Care Because of COVID-19-Related Concerns - United States, June 2020. MMWR Morb Mortal Wkly Rep. 2020;69(36):1250-7.

19. Chudasama Y V., Gillies CL, Zaccardi F, Coles B, Davies MJ, Seidu S, et al. Impact of COVID-19 on routine care for chronic diseases: A global survey of views from healthcare professionals. Diabetes Metab Syndr Clin Res Rev. 2020;14(5):965-7.

20. Amu H, Dowou RK, Boateng LA, Tarkang EE. Implications of covid-19 for the management of chronic non-communicable diseases in sub-Saharan Africa: Application of the chronic care model. Pan Afr Med J. 2020;35(Suppl 2):94.

21. Singh K, Kondal D, Mohan S, Jaganathan S, Deepa M, Venkateshmurthy NS, et al. Health, psychosocial, and economic impacts of the COVID-19 pandemic on people with chronic conditions in India: a mixed methods study. BMC Public Health. 2021;21(1):685.

22. Barach P, Fisher SD, Adams MJ, Burstein GR, Brophy PD, Kuo DZ, et al. Disruption of healthcare: Will the COVID pandemic worsen non-COVID outcomes and disease outbreaks? Vol. 59, Progress in Pediatric Cardiology. 2020. p. 101254.

23. Jacobson AM, Hauser ST, Willett J, Wolfsdorf JI, Herman L. Consequences of irregular versus continuous medical follow-up in children and adolescents with insulin-dependent diabetes mellitus. J Pediatr. 2017;131(5):727-33.

24. Lange SJ, Ritchey MD, Goodman AB, Dias T, Twentyman E, Fuld J, et al. Potential Indirect Effects of the COVID-19 Pandemic on Use of Emergency Departments for Acute Life-Threatening Conditions — United States, January-May 2020. MMWR Morb Mortal Wkly Rep. 2020;69:795-800. 
American Journal of Health, Medicine and Nursing Practice

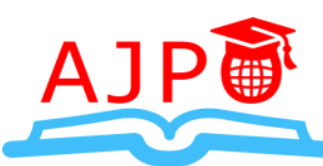

ISSN 2520-4017 (Online)

Vol.6, Issue 3, pp 53 - 65, 2021

www.ajpojournals.org

25. Adom D, Adu Mensah J. The Psychological Distress and Mental Health Disorders from COVID-19 Stigmatization in Ghana. SSRN Electron J. 2020;100186. 